\title{
ЭПИЧЕСКИЕ ВКЛЮЧЕНИЯ В ЯЗЫКЕ ДРАМАТУРГИЧЕСКОГО ТЕКСТА Б. БPEXTA
}

В статье автор обращается к драматургическому дискурсу XX в., а именно к драматургии Б. Брехта. Под ним в работе понимается совокупность текстов, в которых описана система драматургических приемов и принципов театральной игры, и непосредственно текстов «эпических» драм. Такое понимание обусловлено анализом текста сквозь призму аутодескрипции, которая является основным направлением в рамках когнитивно-дискурсивной парадигмы знаний.

Автор делает предположение о том, что тексту «эпической» драмы, как и художественному тексту, свойственно наличие интертекстуальной связи, которая выражена в форме цитирования слов различных авторов, а также в фрорме авторских включений. К таким элементам он относит «зонги» и речитативы. Кроме того, в статье путем сравнительного анализа выделяются основные отличительные черты речитатива и «зонга».

«Зонг» Б. Брехта характеризуется как разновидность «текста в тексте» с особой синтаксической структурой, типичной для лирических произведений. В рамках данного вопроса автор анализирует их семантическую и структурную типологию. Благодаря структурному анализу выделяются такие виды «зонгов», как монолог, диалог и хор.

Анализируя содержание «зонгов»-монологов, автор предполагает, что речь, находящаяся в речеведении одного действующего лица, представ- ляет собой монологический рассказ, раскрывающий основные темы и проблемы произведения. В «зонгах»-диалогах прослеживается та же самая направленность, но реплики представляют собой не традиционный вопрос/ответ, а напоминают собой последовательный рассказ единой тематики нескольких действующих лиц. «Зонг»-хор характеризуется как «коллективный» монолог, поскольку он находится одновременно в речеведении нескольких лиц, но в то же самое время не требует ответной реакции от собеседника.

Речитативы в тексте драмы Б. Брехта в противоположность «зонгам» не подчиняются законам поэзии. Для них характерны прозаическая форма выражения и отсутствие заглавия. Их ритмический рисунок характеризуется асимметрией, а интонационная схема имеет сходство с естественной речью.

По семантике автор выделяет элементы в форме дидактического наставления и резюмирования информации.

В итоге автор приходит к выводу, что текст «эпического театра» имеет много общих черт с повествовательными жанрами, что делает его особо интересным и актуальным для современной лингвистической науки.

Ключевые слова: текст в тексте, интертекстуальные связи, зонг, речитатив, эпический элемент, эпическое включение, интертекстуальная связь.

\section{EPIC INCLUSIONS IN THE LANGUAGE OF B. BRECHT'S DRAMATIC TEXT}

In the article the author turns to the dramatic discourse of the XX century, namely to the drama of B. Brecht. The author views it as a set of texts in which a system of dramaturgic techniques and principles of theatrical play is described, and directly the texts of "epic" dramas. This understanding is due to the analysis of the text through the prism of autodescription, which is the main direction within the cognitive-discursive paradigm of knowledge.

The author assumes that the text of "epic" drama, as well as the artistic text, is characterized by the presence of an intertextual connection, which is expressed in the form of quoting the words of various authors, as well as in the form of author's inclusions. Such elements in B. Brecht's dramas are the "songs" and recitatives. In addition, the article distinguishes the main distinctive features of a recitative and a "song" by means of comparative analysis.

B. Brecht's "song" is characterized as a kind of "text in the text" with a special syntactic structure typical of lyrical works. Within the framework of this issue, the author analyzes their semantic and structural typology. Thanks to the structural analysis, these types of "songs" are distinguished. These are a monologue, a dialogue and a chorus. 
Analyzing the content of such monologues, the author assumes that the speech, which refers to one actor, is a monologic story that reveals the main themes and problems of the work. The "songs"-dialogs follow the same direction, but the replicas are not a traditional question / answer, but they remind us of a consistent story on a single theme of several acrors. "Song"-chorus is characterized as a "collective" monologue, because it is simultaneously in the speech of several persons, but at the same time does not require a response from the interlocutor.

The recitative in the drama text by $\mathrm{B}$. Brecht as opposed to the "songs" does not follow the laws of

Современная лингвистика развивается и расширяет границы своих интересов, сливаясь с другими областями знаний. В данный момент активно набирает обороты аутодескриптивное направление в рамках новой парадигмы знания, которую многие авторы называют когнитивно-дискурсивной [3, с. 519]. Так наиболее перспективным и недостаточно изученным в данном аспекте является текст «эпического театра», который представляет собой синтез элементов повествовательных жанров и драмы. В работе под ним будет пониматься единообразное смысловое пространство или целостная единица, система которой состоит из коммуникативно-функциональных элементов, служащих для осуществления коммуникации в соответствии с речевой ситуацией.

Для анализа «эпических» элементов в текстах драм Б. Брехта был выбран семиотический метод, структурно-семантический и прагматический анализ, метод сплошной выборки фрагментов, содержащих искомый языковой феномен, дистрибутивный метод анализа, а также метод двуязычного перевода. Материалом для исследования послужил драматургический дискурс XX в., представленный «эпическими» драмами Б. Брехта.

Если опираться на аутодескриптивные данные Б. Брехта, то под текстом «эпического театра» можно рассматривать не только совокупность текстов, в которых описана система драматургических приемов и принципов игры в театре, но и все многообразие текстов «эпических» драм. Любой текст является единым смысловым пространством, в который могут быть внедрены разнообразные элементы из других текстов. В свою очередь текст «эпического театра» тоже представляет собой сложную систему, характеризующуюся наличием «текста в тексте» (Ю. М. Лотман). Другими словами, это «введение в оригинальный авторский текст чужого текста» [5, с. 104-122]. poetry. They are characterized by a prosaic form of expression and the absence of a title. Their rhythmic pattern is characterized by asymmetry, and the intonation scheme is similar to natural speech.

In semantics, the author singles out the elements in the form of didactic instruction and summary information. As a result, the author concludes that the text of the "epic theater" reveals many similarities to the narrative genres, which makes it particularly interesting and relevant for modern linguistic science.

Key words: text in the text, intertextual links, song, recitative, epic element, epic inclusion, intertextual connection.

Н. С. Валгина рассматривает особенности оформления художественного текста. По ее мнению, текст может обрамлять основной текст, «передавать главную идею произведения (эпиграф), являться вкраплениями другого языка» [1, с. 94-95]. В качестве примера лингвист приводит использование французского языка в текстах произведений «Война и мир» и «Евгений Онегин». Помимо этого может встречаться непрямое цитирование чужих слов, вставленных в авторский текст без специальных ссылок и выделений.

При этом под драматургическими произведениями сегодня понимаются «такие результаты дискурсивной деятельности, которые представлены в форме пьес; это тексты с особым строением, своей собственной архитектоникой и организацией» [2, с. 4].

Интертекстуальные связи находят свое отражение в различных цитатах: точных и неточных, открытых и скрытых, неявных. Лингвист Н. А. Кузьмина понимает под цитатой «знак интертекста» [4, с. 96]. Она считает, что главными свойствами цитаты является диалогичность. Под диалогичностью исследователь понимает то, что точка зрения, заявленная в цитате, может совпадать с точкой зрения автора метатекста, но не сливается с ней, пока цитата осознается как высказывание другого лица. Кроме того, еще одним важным свойством цитаты является узнаваемость формы, т.е. для автора «чужое слово» становится формой передачи своего собственного смысла, отодвигая на периферию его первичное значение, «оставляя его в виде фрона, нередко контрастного по отношению к новому значению (как, например, в пародии)» [4, с. 101-102].

Лингвистический анализ текстов драм Б. Брехта позволяет определить следующие разновидности интертекстуальных связей в них:

1) Цитирование слов других авторов

Анализ содержания произведений Б. Брехта позволяет утверждать, что его текст харак- 
теризуется введением в авторский метатекст чужого текста. Приведем пример включения цитаты В. В. Маяковского из произведения «Der kaukasische Kreidekreis» (Кавказский меловой круг): «Wie der Dichter Majakowski gesagt hat, "die Heimat des Sowjetvolkes soll auch die Heimat der Vernunft sein»!» [7, p. 11].

2) Введение авторских элементов

В данном случае следует понимать введение автором в метатекст собственных слов, представляющих собой отдельные текстуальные единства, которые отличаются друг от друга литературной формой и даже жанром. В метатексте Б. Брехта к таким единицам относятся «эпические» включения («зонги» и речитативы), т.к. он включает в себя не только сценические диалоги и ремарки, которые являются строительным материалом любого драматургического произведения.

«Зонги» В тексте «эпического театра» представляют собой иную текстуальную форму по сравнению с репликами и ремарками. Согласно немецкому словарю Duden, «зонг» - это песня (музыкальное произведение) (разг.); (музыкально и текстуально простая форма) декламация легко запоминающегося текста под музыкальное сопровождение на злободневную, социально-критическую, сатирическую тематику [10].

«Зонги» Б. Брехта представляют собой особый вид «текста в тексте», который обращает на себя внимание синтаксической структурой, типичной для лирических произведений. Во-первых, в большинстве случаев «зонги» имеют заглавия («Das Lied vom Rauch» («Песня о дыме»), «Lied des Wasserverkäufers im Regen» («Песня водоноса под дождем») и др.). Если же автор не озаглавил данную часть текста, то он использует ремарку «Er singt» (OH поет), «Sie singt» (Она поет). Во-вторых, «зонги» обладают таким свойством, как рифрма.

В произведениях «эпического театра» Б. Брехт использует еще одну вокальную музыкальную фрорму, которая была характерна для творчества народных сказителей - речитатив. Под этим термином принято понимать определенный элемент оперы или род вокальной музыки, приближающийся к естественной речи при сохранении фиксированного музыкального строя и регулярной ритмики. Данный прием применяется в опере, оратории, кантате, а также в песнях.

Речитативы у Б. Брехта являются прозаическими и, как правило, лишены заглавия. В большинстве случаев они представляют собой речь, доведенную до предельно высокой степени выразительности. Они не подчиняются симметрическому ритму и воспроизводят интонационный и ритмический рисунок естественной речи. Чтобы увидеть разницу в синтаксической структуре «зонгов» и речитативов в тексте Б. Брехта, приведем пример каждого из них.

\section{Речитатив:}

"SHEN TE Ich bin erschrocken. Sicher wollten Sie es nur tun, weil der Abend so trüb ist.

\section{Zum Publikum:}

In unserem Lande

Dürfte es trübe Abende nicht geben

Auch hohe Brücken über die Flüsse

Selbst die tuned zwischen Nacht und Morgen

Und die ganze Winterzeit dazu, das ist gefährlich...» [6, p. 47].

«ЗОнг»:

SHEN TE

Es ist schön im Regen.

Wang, der Wasserverkäufer, kommt. Er singt das

«LIED DES WASSERVERKAEUFERS IM REGEN»

Ich hab Wasser zu verkaufen

Und nun steh ich hier im Regen

Und ich bin weithin gelaufen

Meines bisschen Wassers wegen...» [6, p. 50].

Из приведенного выше примера видно, что идентификатором последующего речитатива может служить ремарка «zum Publikum» («Публике»). Несмотря на прозаическую фрорму, речитатив имеет ту же самую структуру, что и стихотворное произведение. Но автор не всегда использует ремаркирование. В таких случаях речитатив отличается только графическим офрормлением.

«Зонги» Б. Брехта в драматургическом тексте оформлены в виде таких фоорм организации речевого ряда, как монолог и диалог. Кроме того, к ним также относится особая форма хор. Для иллюстрации данного утверждения можно привести следующие примеры:

1) Зонг-монолог, в котором речь персонажа не обращена непосредственно к собеседнику с целью получения ответной реакции:

«Grusche singt:

Vier Generäle

Zogen nach Iran

Der erste führte keinen Krieg

Der zweite hatte keinen Sieg

Dem dritten war das Wetter zu schlecht

Dem vierten kämpften die Soldaten nicht recht...» [9, p. 35-36].

В данном типе «зонга» слова могут принадлежать либо певцу, либо одному из персонажей. 
Тема может раскрываться монологически в присутствии других лиц или при их отсутствии.

2) Зонг-диалог, в котором могут участвовать два и более лица:

"ÜBERDIEUNSICHERHEITMENSCHLICHER VERHÄLTNISSE

POLLY

Was ich möchte, ist es viel?

Einmal in dem Tristen Leben

Einem Mann mich hinzugeben.

Ist das ein zu hihes Ziel?

PEACHUM mit der Bibel in den Händen:

Das Recht des Menschen ist's auf dieser Erden

Da er doch nur kurz lebt, glücklich zu sein

Teilhaftig aller Lust der Welt zu warden

Zum Essen Brot zu kriegen und nicht einen Stein.

\section{FRAU PEACHUM}

Wie gern wär ich zu dir gut

Alles möchte ich dir geben

Dass du etwas hast vom Leben

Weil man das doch gerne tut...» [9, p. 42].

Тема в таких «зонгах» может быть раскрыта диалогически в речеведении двух и более персонажей. При этом реплики действующих лиц представляют собой не типичный вопрос/ ответ, утверждение/отрицание, утверждение/ уточнение как в традиционном диалоге, а напоминают собой последовательный рассказ на одну тему.

3) Зонг-хор, который исполняется коллективом или группой действующих лиц, совместно читающих стихи или выступающих с песней:

«CHOR

Horch, wer kommt!

Des Königs reitender Bote kommt!» [9, S. 97]

Данный тип «зонга» можно охарактеризовать как «коллективный» монолог, поскольку он находится одновременно в речеведении нескольких лиц, но в то же самое время не требует ответной реакции от собеседника.

Анализ текстов пьес для «эпического театра» позволяет представить семантическую типологию «зонгов» Б. Брехта следующим образом:

1. Дидактическое наставление (учебные, императивные «зонги»)

Как правило, наличие этих видов «зонгов» характерно для «учебных» пьес, к которым относятся «Исключение и правило» («Die Ausnahme und die Regel»), «Мероприятие» («Die Massnahme), «Горации и Куриации» («Die Horatier und die Kuriatier»). При этом «учебный» характер создается главным образом благодаря дидактичности «зонгов» и песен. Приведем пример из произведения «Исключение и правило» («Die Ausnahme und die Regel»):
«Was nicht fremd ist, findet befremdlich!

Was gewöhnlich ist, findet unerklärlich!

Was da üblich ist, das soll euch erstaunen!

Was die Regel ist, das erkennt als Missbrauch!» [8, p. 4].

Автор задает поучительный тон, т.к. обращается к читателю (зрителю), используя императивное наклонение "findet» (воспринимайте), "schafft Abhilfe» (окажите помощь), а также при помощи модального глагола долженствования «sollen» («das soll euch erstaunen» (это должно вас удивлять)). Обращение основано на использовании императивных конструкций, в которых заданный эффрект усиливается благодаря использованию антонимических лексем: gewönlich (привычный) - unerklärlich (непонятный), Regel (правило) - Missbrauch (нарушение).

\section{2. Резюмирование и оценка информации}

Этот тип «зонгов» можно условно разделить на два вида: 1) обращение к читателю (зрителю) от лица героев; 2) обращение к читателю (зрителю) от лица рассказчика или народного певца (ашуга).

Приведем пример, иллюстрирующий первую категорию:

"Drei Tage ist es her, seit die Goetter weggezogen sind. Sie sagten, sie wollten mit ihr Nachtlager bezahlen. Und als ich sah, was sie mir gegeben haetten, sah ich, dass es ueber tausend Silberdollar waren. - Ich habe mir mit dem Geld einen Tabakladen gekauft. Gestern bin ich hier eingezogen, und ich hoffe, jetzt viel Gutes tun zu koennen» [6, p. 18].

Из приведенного примера понятно, что монолог резюмирует информацию, с которой читатели (зрители) уже знакомы. Читатель (зритель) имеет возможность оценить всю ситуацию с новой стороны, что помогает ему быть более объективным и критично подойти к проблеме, о которой идет речь в произведении. Также это помогает создать эфффект присутствия автора (рассказчика) в произведении или на сцене. Реализация принципа происходит опосредованно, через героя (актера).

Вторая категория этого типа «зонгов» характеризуется наличием слов рассказчика или народного певца (ашуга). Эти лица остаются за пределами основного сюжета, но при этом дополняют и оценивают происходящее со стороны. Рассказчик (певец) управляет ходом действия, но не вмешивается в него и не лишает действующих лиц самостоятельности. В качестве примера можно привести следующий фрагмент из произведений «Кавказский меловой круг» («Der kaukasische Kreidekreis»): 
«Ihr aber, ihr Zuhörer der Geschichte vom Kreidekreis

Nehmt zur Kenntnis die Meinung der Alten:

Daß da gehören soll, was da ist, denen, die für es gut sind,

also

Die Kinder den Mütterlichen, damit sie gedeihen

Die Wagen den guten Fahrern, damit gut gefahren wird

Und das Tal den Bewässerern, damit es Frucht bringt» [7, p. 131].

Итак, понятие «зонг» стало известно именно с появлением «эпического театра» Б. Брехта. Их синтаксическая и графическая структура имеет сходство с лирическими и прозаическими произведениями. Поскольку эти единицы в некотором смысле автономны по отношению к остальному тексту, то была сделана попытка классифицировать их по структуре и семантическому значению.

Стоит отметить, что текст «эпической» драмы Б. Брехта благодаря внедрению в него интертекстуальных элементов сближается с повествовательными жанрами произведений. Текст имеет сходство со сценическим рассказом или сценическим повествованием. Благодаря смещению акцента с реплик на «зонги» меняется роль диалога как основного средства создания речевого портрета персонажа. Это говорит о том, что текст «эпического театра» Б. Брехта содержит некоторое количество ресурсов для современных исследований в области лингвистики текста.

\section{Литература}

1. Валгина Н.С. Теория текста. М.: Логос, 2003. 191 с.

2. Кубрякова Е.С., Александрова О.В. Драматургические произведения как особый объект дискурсивного анализа (к постановке проблемы) // Известия РАН. Серия литературы и языка. Т. 67. 2008. № 4. С.3 - 10.

3. Кубрякова Е.С. Язык и знание. М.: Языки славянской культуры, 2004. 560 с.

4. Кузьмина Н.А. Интертекст и его роль в процессах эволюции поэтического языка. Екатеринбург: Изд-во Уральского ун-та; Омск: Омский гос. ун-т, 1999. 268 с.

5. Лотман Ю.М. Культура и взрыв. М.: Гнозис, Издательская группа «Прогресс», 1992. 272 с.

6. Brecht B. Der gute Mensch von Sezuan. Berlin: Suhrkamp Verlag, 71. Auflage, 2012. $128 \mathrm{~s}$.

7. Brecht B. Der kaukasische Kreidekreis. Berlin: Suhrkamp Verlag, 1963. 131 S.

8. Brecht B. Die Ausnahme und die Regel. Frankfurt-am-Main: Suhrkamp Verlag, 2003. $338 \mathrm{~s}$.

9. Brecht B. Die Dreigroschenoper. Nach John Gays "The Beggar's Opera". Mitarbeiter: E.Hauptmann, K.Weill. Berlin: Aufbau, 1973. $106 \mathrm{~s}$.

10. Duden URL: https://www.duden.de/woerterbuch (Дата обращения: 21.05.2018).

References

1. Valgina N.S. Teorija teksta (Text theory). Moscow: Logos, 2003. 191 p. (In Russian).

2. Kubrjakova E.S., Aleksandrova O.V. Dramaturgicheskie proizvedenija kak osobyj ob'ekt diskursivnogo analiza (k postanovke problemy) (Dramatic texts as a special object of discursive analysis (Introducing the problem) // Izvestija RAN. Serija literatury i jazyka. Vol. 67. 2008. No. 4. P.3 - 10. (In Russian).

3. Kubrjakova E.S. Jazyk i znanie (Language and knowledge). Moscow: Jazyki slavjanskoj kul'tury, 2004, 560 p. (In Russian).

4. Kuz'mina N.A. Intertekst i ego rol' v processah jevoljucii pojeticheskogo jazyka (Intertext and its role in the process of poetic language evolution). Ekaterinburg: USU publ.. Omsk: OSU publ., 1999, 268 p. (In Russian).

5. Lotman Yu.M. Kul'tura i vzryv (Culture and explosion). Moscow: Gnozis, Izdatel'skaja gruppa «Progress», 1992. 272 p. (In Russian).

6. Brecht B. Der gute Mensch von Sezuan. Berlin: Suhrkamp Verlag, 71. Auflage, 2012. 128 p.

7. Brecht B. Der kaukasische Kreidekreis. Berlin: Suhrkamp Verlag, 1963, 131 p.

8. Brecht B. Die Ausnahme und die Regel. Frankfurt-am-Main: Suhrkamp Verlag, 2003, 338 p.

9. Brecht B. Die Dreigroschenoper. Nach John Gays "The Beggar's Opera”. Mitarbeiter: E.Hauptmann, K.Weill. Berlin: Aufbau, 1973, 106 p.

10. Duden URL: https://www.duden.de/woerterbuch (Accessed: 21.05.2018). 